\title{
Case Series: Organophosphate Contamination of Camel's Mammary Glands Affects Human Health
}

\author{
Maryam Saif Al Ali ${ }^{a} \quad$ Jasem Al Shamsi ${ }^{a} \quad$ Saweera Sabbar ${ }^{b}$ \\ aEmergency Department, Rashid Hospital Trauma Center, Dubai Health Authority, Dubai, United Arab Emirates; \\ ${ }^{b}$ Emergency Department, Cleveland Clinic, Abu Dhabi, United Arab Emirates
}

\section{Keywords}

Organophosphate $\cdot$ Pesticides · Cholinergic toxicity ·

Camel milk

\section{Abstract}

In this case series, we present 2 cases of previously healthy farmers, who presented with symptoms of a cholinergic crisis that developed several hours after ingestion of camel milk. The initial case was treated with supportive medical care without using antidote as no history of direct exposure to pesticides was available.The second case presented with symptoms of cholinergic crisis that developed several hours after the ingestion of camel milk. Clinical features included slurred speech, headache, vomiting, diarrhea, frequent micturition, muscle fasciculation, chest discomfort, and atrial fibrillation. The patient developed bradycardia that responded to intravenous atropine. Routine investigations were unremarkable, but acetylcholinesterase and pseudocholinesterase levels were both low. The patient was managed with intravenous fluids, analgesia, atropine, and pralidoxime, which were administered when he developed respiratory symptoms secondary to excessive secretions. The following day, the patient was asymptomatic and dis- charged. On the medical history, the patient denied any other ingestion including food and drink or potential organophosphate exposure on the day of symptom onset. Application of organophosphate pesticides to the mammary glands of camels has been used for many decades against Sarcoptes scabei cameli, a mite that causes a dermal infestation in camels similar to human scabies infections.

(C) 2020 The Author(s)

Published by S. Karger AG, Basel

\section{Introduction}

Camel milk is one of the famous and common traditional drinks in Arabian Gulf countries as it is considered to be beneficial in many aspects. Several studies have shown that it is effective in improves general well-being, promotes body natural defenses by enhancing immunity, and can provide part of the daily nutritional needs for both adults and children [1-3].

Some of the Bedouins (Arab people who have historically inhabited the desert region) would apply organophosphate-like substances to the mammary gland of the camels before milking them in order to protect it from mites. Such intervention when done might result in the

$\begin{array}{ll}\text { karger@karger.com } & \text { (c) 2020 The Author(s). } \\ \text { Pww.karger.com/dmj } & \text { Published by S. Karger AG, Basel } \\ \text { Targer } & \text { This article is licensed under the Creative Commons Attribution- } \\ \text { NonCommercial-NoDerivatives 4.0 International License (CC BY- } \\ \text { NC-ND) (http://www.karger.com/Services/OpenAccessLicense). } \\ \text { Usage and distribution for commercial purposes as well as any dis- } \\ \text { tribution of modified material requires written permission. }\end{array}$


cholinergic crises to people drinking the milk if the mammary gland was not washed and cleaned well prior to milking.

We present here 2 cases of organophosphate toxicity among patients presenting with history of drinking camel milk. We aim to red-flag the importance of asking about traditional use of organophosphate substances prior to milking the camel when dealing with symptoms of cholinergic crisis in emergency setting.

\section{Case Report/Case Presentation}

Case 1

A 45-year-old Asian man presented to emergency department (ED) with generalized body weakness, dizziness, sweating, abdominal pain, passing urine, and loose watery stool. All the symptoms started immediately after the ingestion of fresh camel milk in a farm. The patient admitted that he never drank camel milk before. He denied any chest pain, shortness of breath, fever, or loss of consciousness. The patient's companion did not notice any abnormal movement of the body (e.g., seizures). The patient was a farmer who had no significant medical or surgical history. He denied having any drug allergies, he denied smoking, alcohol consumption or use of any unlawful drugs. On physical exam, the vital signs were as follows: blood pressure 137/90, pulse rate 90 beat per minute, respiratory rate 20 breaths per minute, oxygen saturation $99 \%$ in room air, temperature 34.9 celcius, and random blood sugar -158 $\mathrm{mg} / \mathrm{dL}$. The patient was profusely sweating, looking anxious, having dysarthria, but no tongue bite was evident. The patient had urinary and fecal incontinence. There were no rashes on his body, and no other clinical findings were present on systemic examination except for generalized weakness. Laboratory test was unremarkable except for hypokalemia (potassium level $2.6 \mathrm{mmol} / \mathrm{L}$ ), electrocardiogram showed normal sinus rhythm, and computed tomography (CT) brain with contrast showed left middle cerebral artery to be hyper-dense, suspecting acute thrombosis. Despite such results from the brain CT, cerebrovascular accident was kept as one of the differential diagnoses but not primary since the overall picture was suggesting a cholinergic toxidrome. The patient was admitted under observation, and he was managed with intravenous fluids and given potassium chloride replacement because of his hypokalemia, and he was improved gradually with complete recovery and discharged.

\section{Case 2}

A 30-year-old Asian man presented to the ED with slurred speech, headache, vomiting, loose motion, frequent urination, and chest discomfort. All the symptoms started on the same day of ingestion fresh farm camel milk. The patient complained of not feeling well and having headache, vomiting, diarrhea, and frequent urination. He also had chest discomfort and palpitation. The patient's friends also noticed that the patient had left-sided body weakness. He was a farmer who had no significant medical or surgical history. He denied having any drug allergies, he denied smoking, alcohol consumption or use of any unlawful drugs. On examination, vital blood pressure was 105/77, pulse rate 102 beat per minute, RR 20 breaths per minute, oxygen saturation $99 \%$ in room air, temperature 35.4 celcius, random blood sugar $-221 \mathrm{mg} / \mathrm{dL}$, and electrocardiogram was also taken initially which showed atrial fibrillation. The patient was conscious, alert, but irritable. Systemic examination was normal except for an irregular heartbeat. Pupils were $2 \mathrm{~mm}$ and reactive. During the assessment, he passed urine over the bed and after few minutes, the patient's heart rate dropped to 30 beats/min, and he complained of feeling dizzy. So atropine $0.5 \mathrm{mg}$ IV was administered, and his heart rate increased. Neurological examination showed no focal neurological defect. During his ED stay, the patient was noted to have some fasciculation and muscle twitching. Laboratory tests were unremarkable, and CT brain was normal. The patient was managed with IV fluids, atropine, and pralidoxime which were administered when he developed respiratory symptoms secondary to excessive secretions. His symptoms improved accordingly, and he was discharged the following day. As the patient was noticed to have cholinergic toxidrome after camel milk ingestion and no other direct exposure to an organophosphate source was reported, serum pseudocholinesterase and acetylcholinesterase levels were sent, and the result was low serum pseudocholinesterase $0.3-\mathrm{kU} / \mathrm{L}$ (normal-5.3-12.9) and acetylcholinesterase (HB) 0.15 - delta- $\mathrm{pH} / \mathrm{h}$ (normal 0.55-0.85) which confirmed our diagnosis. Both patients were followed up, and they did not have any health complaints after hospital discharge.

\section{Discussion}

Organophosphate can be found in pesticides, medication, plants, chemical weapons, or occupational substances. Toxicity can happen from intentional ingestion, medication noncompliance, dermal exposure, or inhalation. Organophosphate toxicity results from inhibiting acetylcholinesterase which results in the accumulation of acetylcholine at the muscarinic and nicotinic receptors. Clinical presentation of toxicity varies with duration, route of exposure, and type of agents. The primary symptoms might be secondary to the widespread of acetylcholine in the central nervous system which will manifest as headache, confusion, seizure, vertigo, or coma. Other presentations can be secondary to the involvement of muscarinic receptors (DUMBBELLS = Diarrhea, Urination, Miosis, Bradycardia, Bronchorrhea, Emesis Lacrimation, Lethargic, Salivation). Nicotinic receptor involvement will manifest as fasciculation, mydriasis, tachycardia, hypertension, seizure, tremor weakness, and paralysis. Diagnosing organophosphate toxicity can be made by clinical suspicion from patient history and physical examination. Specific test of pseudocholinesterase and acetylcholinesterase level, which will be low in organophosphate toxicity, is confirmatory. Management of patients presenting with organophosphate toxicity includes resuscitation and supportive care, decontamina- 
tion of the patient by removing the clothes, and washing the skin and using the antidote (e.g., atropine and pralidoxime).

Awareness of cholinergic crisis after camel milk ingestion is important as the practice of applying acaricides (organophosphate like substance) over the mammillary gland is used as a standard of care for disease prevention and treatment in Arabian camels (Psoroptes cameli) [4]. Our report supports another study that presents the effect of pesticides on farm workers in the United Arab Emirates [5].

\section{Conclusion}

Farmers are at risk of pesticide exposure and toxicity from indirect exposure. A comprehensive history and physical examination can guide physicians to the correct diagnosis and proper management of such patients.

\section{Statement of Ethics}

The authors believe the importance of obtaining a consent before publishing a case report, and based on that, multiple attempts have been tried to communicate with the patient and failed; at the same time, the authors feel that this case should be published to raise awareness among farmers regarding the dangers of such practice through the public health system and to bring the attention of healthcare providers that cholinergic crisis after camel milk ingestion in this particular scenario is a possibility.

\section{Conflict of Interest Statement}

The authors have no conflicts of interest to declare.

\section{Funding Sources}

The authors did not receive any funding.

\section{Author Contributions}

M.S.A.A.: manuscript preparation, literature search, and review. J.A.S.: case presentation, literature search, manuscript preparation, and review. S.S.: case presentation, manuscript review, and editing.

\section{References}

1 Yagil R. Camel milk and its unique anti-diarrheal properties. Isr Med Assoc J. 2013;15(1): 35-6.

2 Zibaee S, Hosseini SM, Yousefi M, Taghipour A, Kiani MA, Noras MR. Nutritional and therapeutic characteristics of camel milk in children: a systematic review. Electron Physician. 2015 Nov;7(7):1523-8.
3 Claeys WL, Verraes C, Cardoen S, De Block J, Huyghebaert A, Raes K, et al. Consumption of raw or heated milk from different species: an evaluation of the nutritional and potential health benefits. Food Control. 2014;42:188201.
4 Moretti J. Husbandry guidelines for Arabian camel Camelus dromedarius. 2008.

5 Beshwari MMM, Bener A, Een AAM, Ehdi AMA, Ouda HZ. Pesticide-related health problems and diseases. Int J Environ Health Res. 1999;221. 